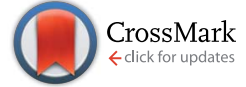

Cite this: RSC Adv., 2017, 7, 3861

\title{
Drug induced micelle-to-vesicle transition in aqueous solutions of cationic surfactants $\uparrow$
}

\author{
Zuber S. Vaid, ${ }^{a}$ Arvind Kumar, ${ }^{\text {b }}$ Omar A. El Seoud ${ }^{\star c}$ and Naved I. Malek ${ }^{* a c}$
}

The effects of the anti-inflammatory drug diclofenac sodium (DS) on the morphology of aqueous micellar aggregates of two ionic liquid-based surfactants (ILBSS), 1-hexadecyl-3-vinylimidazolium bromide, $\mathrm{C}_{16} \mathrm{VnImBr}$, 1-hexadecyl-3-methylimidazolium bromide $\mathrm{C}_{16} \mathrm{MelmBr}$, and (conventional) cetyltrimethylammonium bromide, $\mathrm{C}_{16} \mathrm{Me}_{3} \mathrm{ABr}(\mathrm{Vn}, \mathrm{Im}, \mathrm{Me}, \mathrm{A}=$ vinyl, imidazolium, methyl and ammonium, respectively) were studied at $25^{\circ} \mathrm{C}$. To probe the morphology changes of the formed aggregates, we employed turbidity, viscosity, dynamic light scattering, and transmission electron microscopy. Depending on [DS], the transitions observed were from spherical micelles $\rightarrow$ worm-like micelles $\rightarrow$ vesicles. Viscosity data indicated that the first transition occurred at lower [DS] for $\mathrm{C}_{16} \mathrm{VnlmBr}$ compared to $\mathrm{C}_{16} \mathrm{MelmBr}$ and $\mathrm{C}_{16} \mathrm{Me}_{3} \mathrm{ABr}$; indicating stronger interaction between $\left(\mathrm{C}_{16} \mathrm{VnIm}\right)^{+}$and $\mathrm{DS}^{-}$. Light scattering results revealed that the $\mathrm{DS} / \mathrm{C}_{16} \mathrm{VnlmBr}$ system contained larger vesicles, as compared to $\mathrm{DS} / \mathrm{C}_{16} \mathrm{MelmBr}$ and $\mathrm{DS} / \mathrm{C}_{16} \mathrm{Me} \mathrm{e}_{3} \mathrm{ABr}$. The changes in morphology agree with the expected effects of $\mathrm{DS}$ on the packing parameter of the colloidal aggregates.

Received 21st October 2016 Accepted 12th December 2016

DOI: 10.1039/c6ra25577a

www.rsc.org/advances hydrolytic and oxidative degradation in aqueous medium is high. $^{\mathbf{1 1 , 1 2}}$ Vesicle formation of cetyltrimethylammonium bromide $\left(\mathrm{C}_{16} \mathrm{Me}_{3} \mathrm{ABr}\right)$ was induced using 5-methylsalicylic acid, ${ }^{13}$ cholesterol, ${ }^{14}$ and sodium deoxycholate. ${ }^{15}$

Ionic liquids (ILs) are composed only of ions and have, by operational definition, melting points $<100{ }^{\circ} \mathrm{C}$. Due to their structural versatility, they have found applications as solvents, catalysts and for capturing of-, and sensors for carbon dioxide. ${ }^{16-19}$ IL-based surfactants (ILBSs) possess one or more hydrophobic tails, usually attached to a heterocyclic ring (e.g., imidazolium, pyridinium, piperidinium, pyrrolidinium) or amino acid cation (glycine, alanine, valine, proline and glutamic acid). ${ }^{\mathbf{2 0 - 4 2}}$ Aggregation behavior of ILBSs that carry heterocyclic cations was investigated, ${ }^{\mathbf{1 6}-43}$ and the micellar properties were compared with those of conventional surfactants. ${ }^{\mathbf{4 4}}$

The critical micelle concentration, cmc, of ILBSs are usually lower than those of conventional surfactants with the same hydrophobic "tail" and counter-ion. ${ }^{25}$ Few reports were published on vesicle formation by ILBSs, induced by addition of inorganic and organic electrolytes; ${ }^{\mathbf{4 5}}$ oppositely charged ionic surfactants (leading to formation of catanionic systems), ${ }^{\mathbf{4 6 - 4 9}}$ and cholesterol. ${ }^{50}$ For the ILBSs 1-alkyl-3-methylimidazolium bromide series, $\mathrm{C}_{n} \mathrm{MeImBr}(n=10,12,14)$, the transition from spherical micelles to uni-lamellar vesicles was induced by increasing the concentration of the surfactant. ${ }^{51}$

The aim of the present contribution is to probe the effects of diclofenac sodium (DS) on the morphologies of micellar aggregates of 1-hexadecyl-3-vinylimidazolium bromide, $\mathrm{C}_{16} \mathrm{VnImBr}$, 1-hexadecyl-3-methylimidazolium bromide $\mathrm{C}_{16} \mathrm{MeImBr}$ and $\mathrm{C}_{16} \mathrm{Me}_{3} \mathrm{ABr}$ (Vn, Im, Me, $\mathrm{A}=$ vinyl,
${ }^{a}$ Applied Chemistry Department, S. V. National Institute of Technology, Surat 395 007, Gujarat, India.E-mail: navedmalek@yahoo.co.in

${ }^{b}$ Salt and Marine Chemicals Division, CSIR-Central Salt and Marine Chemicals Research Institute, G. B. Marg, Bhavnagar-364002, India

'Institute of Chemistry, The University of São Paulo, 748 Prof. Lineu Prestes Av., São Paulo, SP 05508-000,Brazil..E-mail: elseoud@usp.br

$\dagger$ Electronic supplementary information (ESI) available. See DOI: 10.1039/c6ra25577a 
imidazolium, methyl and ammonium, respectively) for potential therapeutic use, e.g., for drug delivery in topical applications. DS is a non-steroidal drug that is widely prescribed, especially due to its anti-inflammatory effect. Worldwide, it is the twelfth ranking generic prescription drug. ${ }^{52}$ The DS-induced micellar transitions were evaluated at $25{ }^{\circ} \mathrm{C}$ using turbidity, viscosity, dynamic light scattering (DLS), and transmission electron microscopy, TEM. The transitions observed were spherical micelles $\rightarrow$ worm-like micelles $\rightarrow$ vesicles, indicating potential application in drug delivery.

During the preparation of this manuscript, a publication appeared on the effects of the DS on the micellar morphology of the ILBSs 1-R-3-methylimidazolium bromides; $\mathrm{R}=\mathrm{C}_{12}, \mathrm{C}_{12}$ MeImBr and $\mathrm{R}=\mathrm{C}_{14}, \mathrm{C}_{14} \mathrm{MeImBr} .^{53}$ Our data for $\mathrm{C}_{16} \mathrm{MeImBr}$ complete, therefore, this recently published work on the 1-R-3methylimidazolium bromide series. Additionally, we probed the effects of DS on the micellar aggregates of $\mathrm{C}_{16} \mathrm{VnImBr}$, an ILBS whose head-ion carries an unsaturated (vinyl) group, and (conventional) $\mathrm{C}_{16} \mathrm{Me}_{3} \mathrm{ABr}$. We have recently showed that the relative rigidity and less hydrophobic character of the vinyl group (relative to the ethyl group) lead to different micellar properties, including packing of the monomers in the micelles of $\mathrm{C}_{16} \mathrm{VnImBr}$ relative to $\mathrm{C}_{16} \mathrm{EtImBr}(\mathrm{Et}=$ ethyl $) .{ }^{54}$

\section{Experimental}

\section{Materials}

The molecular structures of the materials employed in the present study are depicted in Scheme 1:

The ILBSs $\mathrm{C}_{16} \mathrm{VnImBr}$ and $\mathrm{C}_{16} \mathrm{MeImBr}$ were from a previous study. ${ }^{54} \mathrm{C}_{16} \mathrm{Me}_{3} \mathrm{ABr}$ and DS were purchased from Spectrochem Pvt (Mumbai). Where appropriate, the starting solid materials were dried under reduced pressure. Double distilled, deionized water having conductivity of 6.1-6.4 $\mu \mathrm{S} \mathrm{cm}^{-1}$ was used throughout.

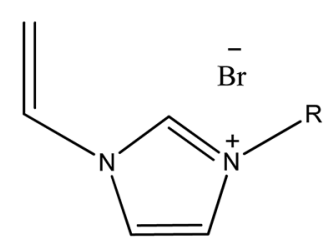

$\mathrm{R}=\mathrm{C}_{16} \mathrm{H}_{33}$.

$\mathrm{C}_{16} \mathrm{VnImBr}$

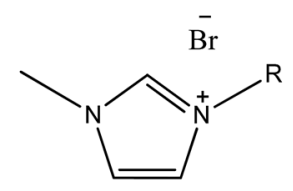

$\mathrm{R}=\mathrm{C}_{16} \mathrm{H}_{33}$

$\mathrm{C}_{16} \mathrm{MelmBr}$

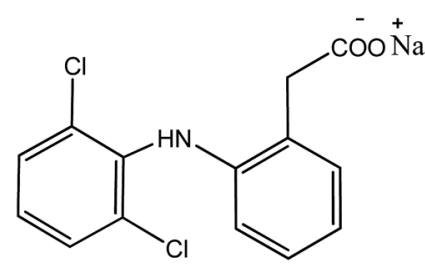

(DS)

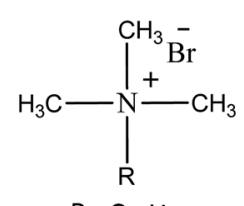

$\mathrm{R}=\mathrm{C}_{16} \mathrm{H}_{33}$.

$\mathrm{C}_{16} \mathrm{Me}_{3} \mathrm{ABr}$
Scheme 1 Molecular structures of the compounds of interest in the present work.

\section{Methods}

Notes: we performed all measurements at $25 \pm 0.1{ }^{\circ} \mathrm{C}$. We prepared solutions of DS in ILBS by mixing the appropriate volumes of aqueous stock solutions of both compounds. The $\mathrm{pH}$ value of all aqueous solutions (before mixing) was carefully adjusted to 6.2 .

\section{Turbidity measurements}

We used Varian Carry 50 spectrophotometer, equipped with a thermostated cell compartment, using $1 \mathrm{~cm}$ path-length quartz cuvettes. Values of the absorbance (A) of the DS/surfactant solutions were recorded at variable [DS], at $\lambda=500 \mathrm{~nm}$, i.e., where the surfactant and DS do not absorb.

\section{Viscosity measurements}

These were performed using Brookfield DV-2 + Pro viscometer.

\section{Dynamic light scattering measurements}

DLS measurements were performed using Zetasizer Nano ZS90 (Malvern). All aqueous solutions were filtered (0.45 micron filter) into the quartz cuvette; the latter was washed several times with the filtered solution before performing the DLS measurement. The distribution of the aggregate diameters was calculated by the cumulants method.

\section{Transmissions electron microscopy measurements (TEM)}

TEM images were recorded on JEM 2100 (JEOL), equipped with a LaB6 gun, operating at $200 \mathrm{kV}$ acceleration voltage. The solution, $10 \mu \mathrm{L}$, was deposited on 200 mesh size Formvar/ carbon-coated copper grid (10 nm Formvar/1 nm carbon film thicknesses) left for $10 \mathrm{~min}$, the excess liquid on the grid was removed, and the residue was stained using $2 \%$ uranyl acetate solution.

\section{Calculation of the micellar packing parameter}

The packing factor $(P)$ was calculated from the equation: $P=v_{\mathrm{t}} /$ $\left(a_{\mathrm{h}} l_{\mathrm{c}, \mathrm{t}}\right)$, where $v_{\mathrm{t}}$ is the volume of the surfactant tail, $a_{\mathrm{h}}$ is the (optimal) area occupied by the surfactant head-group, and $l_{\mathrm{c}, \mathrm{t}}$ is the critical chain length of the tail. ${ }^{55}$ We took $n$-hexadecane as a model for the hydrophobic tail of the surfactants studied. The calculated value of $v_{\mathrm{t}}$ was $=0.488 \mathrm{~nm}^{3}$, based on the molar mass and the density of this hydrocarbon $\left(d=0.7701 \mathrm{~g} \mathrm{~cm}^{-3}\right.$ at $\left.25^{\circ} \mathrm{C}\right) .{ }^{56}$ To calculate $l_{\mathrm{c}, \mathrm{t}}$, we used $0.9 \times l_{\max }$, where $l_{\max }$ is the maximum length of the alkyl chain, as calculated using Tanford's equation: $l_{\max }=0.15+0.1265 N_{\mathrm{C}}$, where $N_{\mathrm{C}}$ is the number of carbons in the alkyl chain $;{ }^{57} l_{\max }=2.174 \mathrm{~nm}$ and $l_{\mathrm{c}, \mathrm{t}}=1.9566 \mathrm{~nm}$.

The values of $a_{\mathrm{h}}$ were calculated using two procedures: (i) for $\mathrm{C}_{16} \mathrm{Me}_{3} \mathrm{ABr}$, we used literature values of the micellar hydrodynamic radius $(2.3 \mathrm{~nm})$ and aggregation number $\left(N_{\mathrm{agg}}=76\right) ;{ }^{58} a_{\mathrm{h}}=0.875$ $\mathrm{nm}^{2}$ per molecule; (ii) the values of $a_{\mathrm{h}}$ for $\mathrm{C}_{16} \mathrm{MeImBr}$ and $\mathrm{C}_{16^{-}}$ $\mathrm{VnImBr}$ was taken as minimum area occupied by the surfactant molecule at the water/air interface; $a_{\mathrm{h}}=0.816 \mathrm{~nm}^{2}$ per molecule for $\mathrm{C}_{16} \mathrm{MeImBr}$, and $0.80 \mathrm{~nm}^{2}$ per molecule for $\mathrm{C}_{16} \mathrm{VnImBr}{ }^{54}$ 
Using the above-mentioned values, we calculated $P=0.285$, 0.306 and 0.312 respectively for $\mathrm{CTABr}, \mathrm{C}_{16} \mathrm{MeImBr}$ and $\mathrm{C}_{16} \mathrm{VnImBr}$.

\section{Results and discussion}

Electrostatic attraction between ionic micelle and an oppositely charged substrate, as well as hydrophobic interactions between both species lead to accumulation of the substrate in the Stern layer of the micelle, a gradual decrease of the micellar surface potential, with concomitant changes of its geometry. These changes include micellar growth, e.g., into viscoelastic wormlike structures, accompanied with a large increase of viscosity and, eventually, formation of (low-viscosity) multi- or unilamellar vesicles. These morphology changes are most readily detected by following the dependence of some physical property
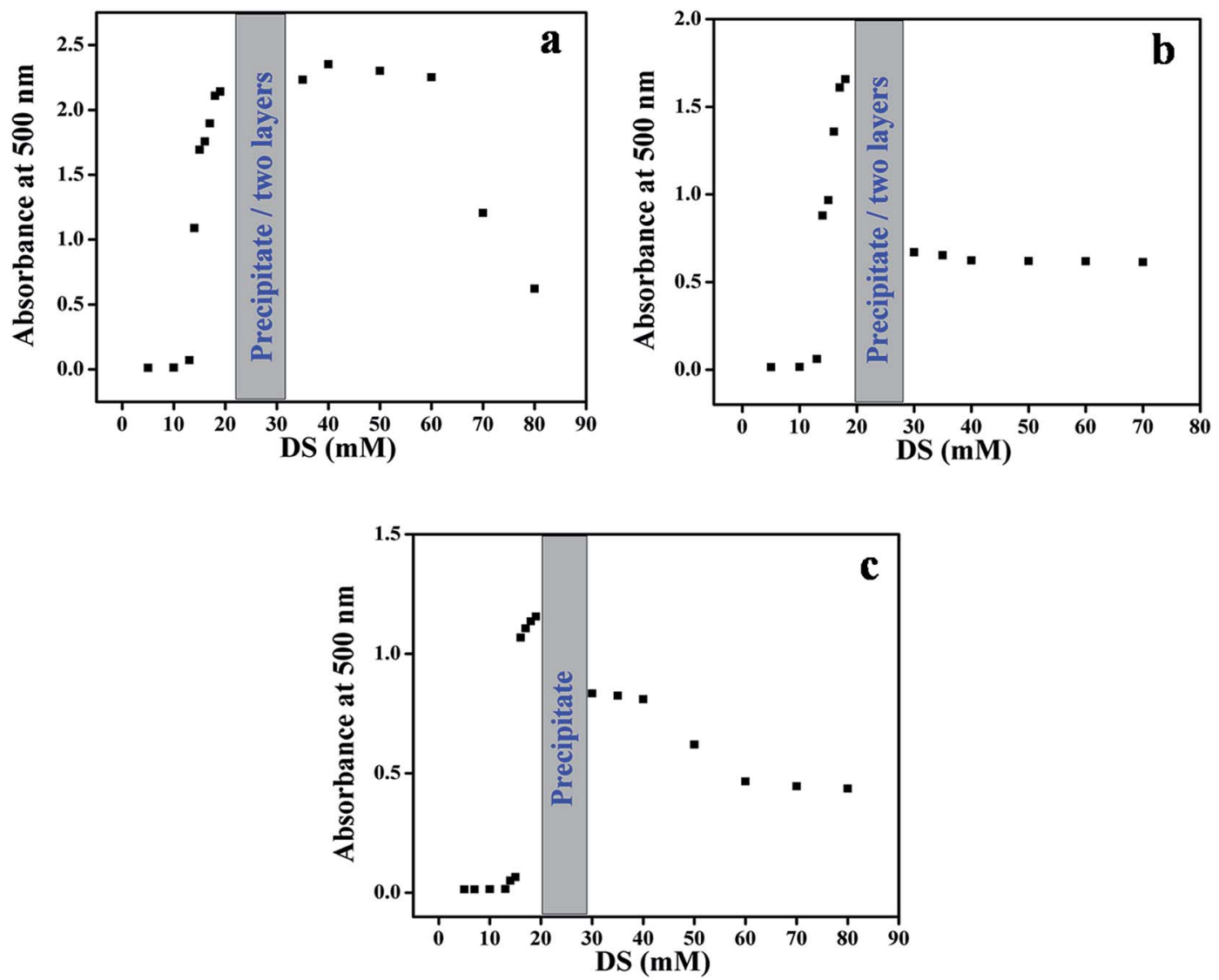

Fig. 1 Dependence of the absorbance at $500 \mathrm{~nm}$ of surfactants solutions (20 mmol) on [DS], for $\mathrm{C}_{16} \mathrm{VnlmBr},(\mathrm{a}) ; \mathrm{C}_{16} \mathrm{MelmBr}$, (b); $\mathrm{C}_{16} \mathrm{Me}{ }_{3} \mathrm{ABr}$, (c).

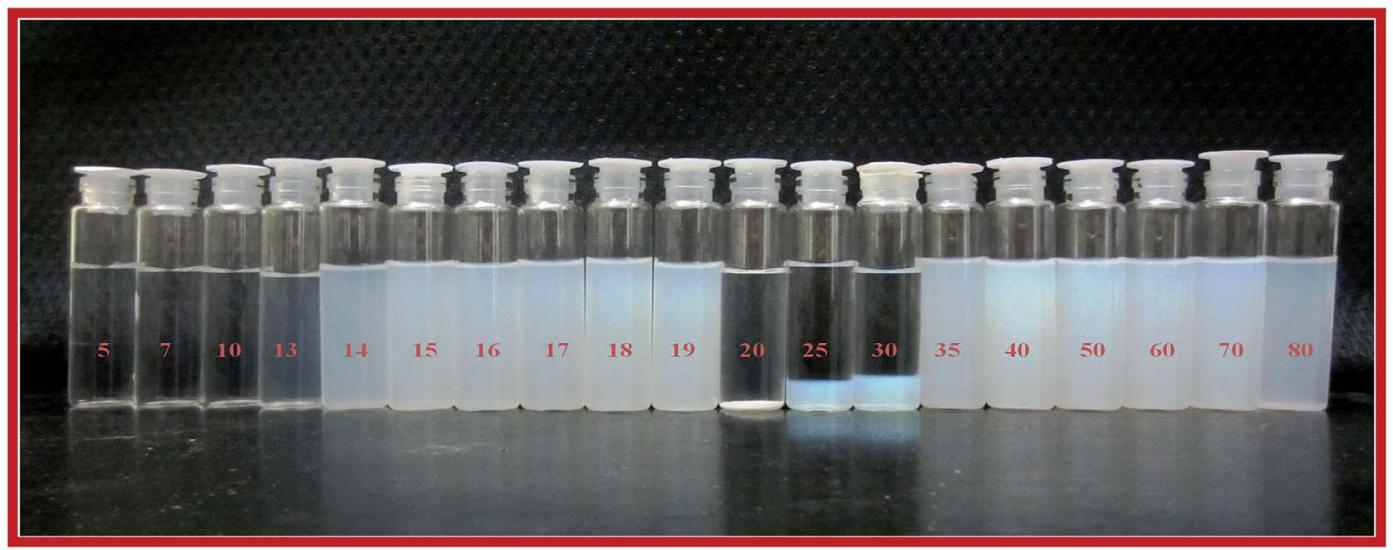

Fig. 2 Image of $\mathrm{DS} / \mathrm{C}_{16} \mathrm{VnlmBr}$ solutions at a constant final surfactant concentration (20 mmol) and variable [DS] from 5 to $80 \mathrm{mmol}$. The final [DS] are written in red numbers. 
of the system on [solubilizate]. The $\mathrm{p} K_{\mathrm{a}}$ of DS in water is 4.16 , i.e., the drug is essentially present as $\left(\mathrm{DS}^{-}\right)$under our experimental conditions. Indeed, when the $\mathrm{pH}$ of the $\mathrm{DS} / \mathrm{C}_{16} \mathrm{VnImBr}$ was decreased to 3 precipitation occurred as shown in Fig. SM-1 (Fig. 1 of ESI) $\dagger$ Consequently, we can safely assume that the above-mentioned micellar changes, if they occur, are due to interactions between the cationic micelle and the anionic drug, as indicated by ${ }^{1} \mathrm{H}$ NMR data of DS in cationic ILBSs. ${ }^{53}$

In addition to conclusions based on the effect of DS on the packing parameter of the aggregates, vide infra, we followed the evolution of several properties of the solution, induced by adding increased concentrations of DS to $20 \mathrm{mmol}$ surfactant. Values of the cmc of the surfactants employed are: $0.40 \mathrm{mmol}$, $0.54 \mathrm{mmol}$ and $1.0 \mathrm{mmol}$, for $\mathrm{C}_{16} \mathrm{VnImBr}$; $\mathrm{C}_{16} \mathrm{MeImBr}$; $\mathrm{C}_{16} \mathrm{Me}_{3} \mathrm{ABr}$, respectively, ${ }^{54,58}$ i.e., all measurements discussed below were done on micellar solutions. The techniques that we employed were turbidity, viscometry, DLS, and TEM. Our results indicated clearly that incorporation of anionic DS into cationic micelles leads to the above-mentioned morphology changes; $\mathrm{C}_{16} \mathrm{VnImBr}$ is more sensitive than the other two surfactants.

\section{Packing parameter}

Our calculated values of $(P)$ for $\mathrm{C}_{16} \mathrm{Me}_{3} \mathrm{ABr}(0.285)$ and $\mathrm{C}_{16^{-}}$ MeImBr (0.306) agree with literature values, 0.29 and 0.27 , respectively. ${ }^{59}$ As expected, in the absence of DS, the three surfactants form micelles with $P<0.5$. Vesicles form at $P$ between 0.5 and 1 . From the equation: $P=v_{\mathrm{t}} /\left(a_{\mathrm{h}} l_{\mathrm{c}, \mathrm{t}}\right)$, this increase in $P$ can result from a decrease in $\left(a_{\mathrm{h}}\right)$ due to the association between negatively charged DS and the surfactant cationic head-group to form contact ion pairs, with partial expulsion of the associated water of hydration (of the components of the catanionic species formed). This coulombic interaction, coupled with solute-surfactant hydrophobic interactions due to the presence of the two atomic rings of the former decrease $\left(a_{\mathrm{h}}\right)$, i.e., increase $(P)$ and eventually lead to vesicle formation. We present below experimental evidence to corroborate our analysis of the expected change in $(P)$ due to DS solubilization.

\section{Turbidity measurements}

As given in experimental, the solution absorbance was recorded at $\lambda$ where the individual system components (DS and the surfactants) do not absorb light. Consequently, we can attribute any change in absorbance as a function of increasing [DS] to light scattering due to drug-induced aggregate morphology change. The results of these experiments are depicted in Fig. 1(a-c); we show images of the resulting solutions in Fig. 2-4.

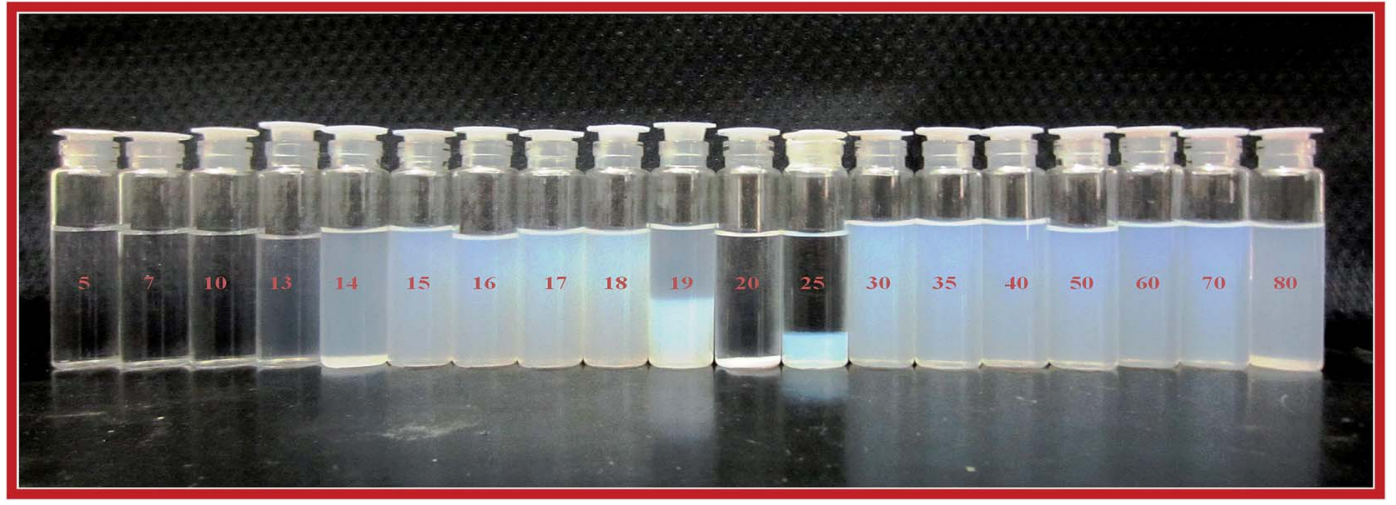

Fig. 3 Image of $\mathrm{DS} / \mathrm{C}_{16} \mathrm{MelmBr}$ solutions at a constant final surfactant concentration and variable [DS]. The concentrations of both components are the same employed for $C_{16} V n l m B r$, values of [DS] in mmol are written in red numbers.

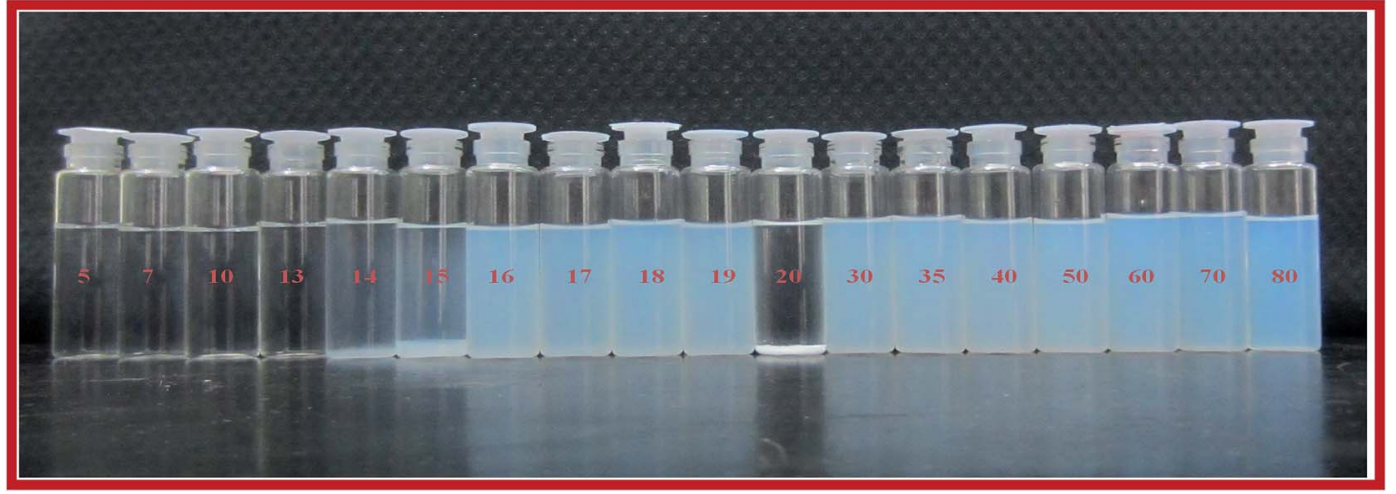

Fig. 4 Image of $\mathrm{DS} / \mathrm{C}_{16} \mathrm{Me}_{3} \mathrm{ABr}$ solutions at a constant surfactant concentration and variable [DS]. The concentrations of both components are the same employed for $\mathrm{C}_{16} \mathrm{VnlmBr}$, values of [DS] in $\mathrm{mmol}$ are written in red numbers. 
As shown in part $(\mathrm{a}-\mathrm{c})$ of Fig. 1, the absorbance remains practically constant until [DS] of $c a .10 \mathrm{mmol}$. At higher [DS], the solutions appear bluish (Tyndall effect), ${ }^{60}$ there is an abrupt increase, and then decreases in absorbance. In all systems we observed precipitation, e.g., at $20 \mathrm{mmol}$ DS. Similar changes were observed when the photo-responsive dye sodium 4-[(E)phenyldiazenyl]benzoate was added to a micellar solution of $\mathrm{C}_{16} \mathrm{Me}_{3} \mathrm{ABr}{ }^{61}$ and are indicative of micelles to vesicles transition. ${ }^{62}$ Additionally in the case of ILBSs we observed phase separation, e.g., at 25 and $30 \mathrm{mmol}$ DS (Fig. 2), 19 and 25 (Fig. 3).

As a function of increasing [DS], the following was observed: the order of [DS] necessary to produce the onset of turbidity was: $\mathrm{C}_{16} \mathrm{Me}_{3} \mathrm{ABr}(16 \mathrm{mmol})>\mathrm{C}_{16} \mathrm{MeImBr}(15 \mathrm{mmol})>\mathrm{C}_{16} \operatorname{VnImBr}(14$ $\mathrm{mmol}$ ). This result can be linked to the following order of surface activity (i.e., the surface tension at the cmc) $\mathrm{C}_{16} \mathrm{Me}_{3} \mathrm{ABr}$ $\left(40.8 \mathrm{mN} \mathrm{m}^{-1}\right)>\mathrm{C}_{16} \operatorname{MeImBr}\left(34.2 \mathrm{mN} \mathrm{m}^{-1}\right)>\mathrm{C}_{16} \operatorname{VnImBr}(33.5$ $\left.\mathrm{mN} \mathrm{m}{ }^{-1}\right) .^{54}$

The oppositely charged $\mathrm{DS}^{-}$and $\mathrm{C}_{16} \mathrm{Me}_{3} \mathrm{ABr}$ interact electrostatically as well as hydrophobically (between DS aromatic rings and the surfactant hydrophobic tail). The same mechanisms are operative for the ILBSs, in addition to interactions between $\pi$ electrons of the drug, the surfactant heterocyclic ring and, for $\mathrm{C}_{16} \mathrm{VnImBr}$, the vinyl group. ${ }^{63}$ The higher value of turbidity for the $\mathrm{DS} / \mathrm{C}_{16} \mathrm{VnImBr}$ system indicates the formation of larger size uni-lamellar vesicles as compared with the DS/
$\mathrm{C}_{16} \mathrm{MeImBr}$ and $\mathrm{DS} / \mathrm{C}_{16} \mathrm{Me}_{3} \mathrm{ABr}$ counterparts. ${ }^{64}$ This conclusion is corroborated by our DLS and TEM results, vide infra. We found that the precipitation and phase separation regions for the ILBSs, and the precipitation for $\mathrm{C}_{16} \mathrm{Me}_{3} \mathrm{ABr}$ occur close to equimolar ratio of DS/amphiphilic molecules as shown in Fig. 1. A similar behavior was observed when sodium-3-hydroxy2-naphthoate was added to $\mathrm{C}_{16} \mathrm{Me}_{3} \mathrm{ABr} .^{65}$

\section{Viscosity measurements}

Fig. 5 shows the changes in viscosity as a function of increasing [DS] for the three (drug/surfactant) systems.

ILBSs generally form spherical micelles at concentrations above their cmc. ${ }^{43,51}$ On comparing Fig. 1 and 5, we observe that with increasing the concentration of DS, viscosity and optical density data changed in similar manner. The increase in viscosity indicates the change in morphologies of micelles from spherical to elongated shape. At concentration of $13 \mathrm{mmol}$ of DS, the viscosity reaches its maximum value, and the solution becomes viscoelastic, as indicated by trapping of air bubbles for long periods of time, Fig. 5. The steep increase in viscosity occurred at lower concentration of DS for $\mathrm{C}_{16} \mathrm{VnImBr}(7 \mathrm{mmol})$ compared to $\mathrm{C}_{16} \mathrm{MeImBr}(8 \mathrm{mmol})$ and $\mathrm{C}_{16} \mathrm{Me}_{3} \mathrm{ABr}(10 \mathrm{mmol})$ as shown in insets of Fig. 5. This indicates electrostatic and hydrophobic interactions of the drug with the head-group of
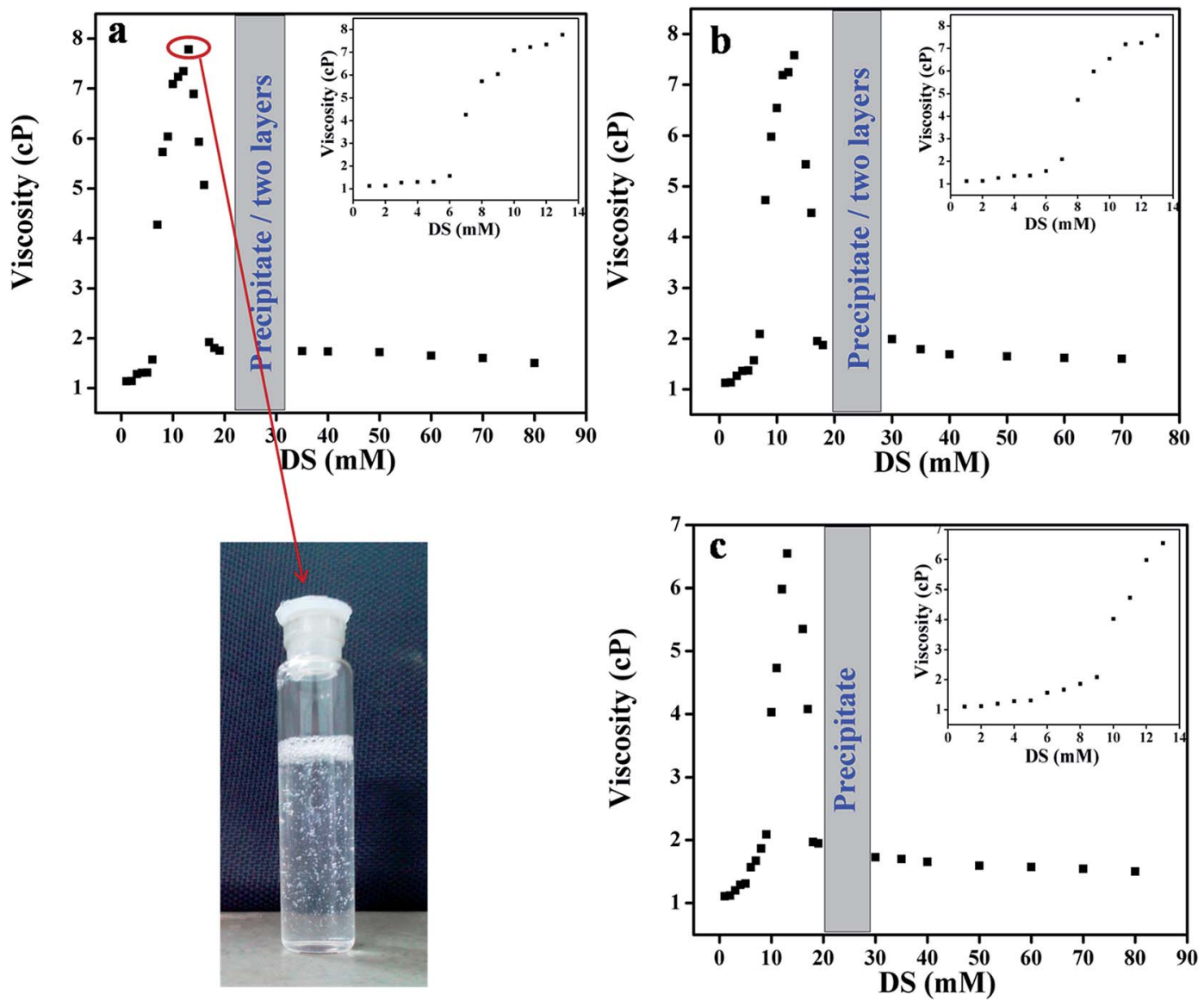

Fig. 5 Viscosity changes as a function of increasing [DS] in aqueous solution of $20 \mathrm{mmol}$ (a) $\mathrm{C}_{16} \mathrm{VnlmB}$, (b) $\mathrm{C}_{16} \mathrm{MelmBr}$ and (c) $\mathrm{C}_{16} \mathrm{Me} \mathrm{e}_{3} \mathrm{ABr}$. 


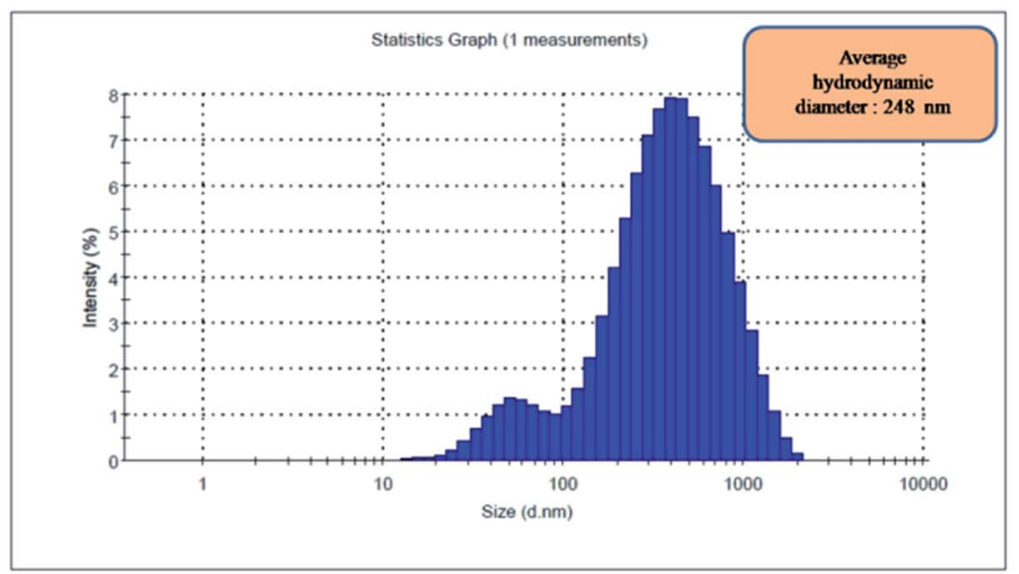

\section{A- $20 \mathrm{mmol} \mathrm{C}_{16} \mathrm{VnImBr}$ in the presence of $18 \mathrm{mmol} \mathrm{DS}$}

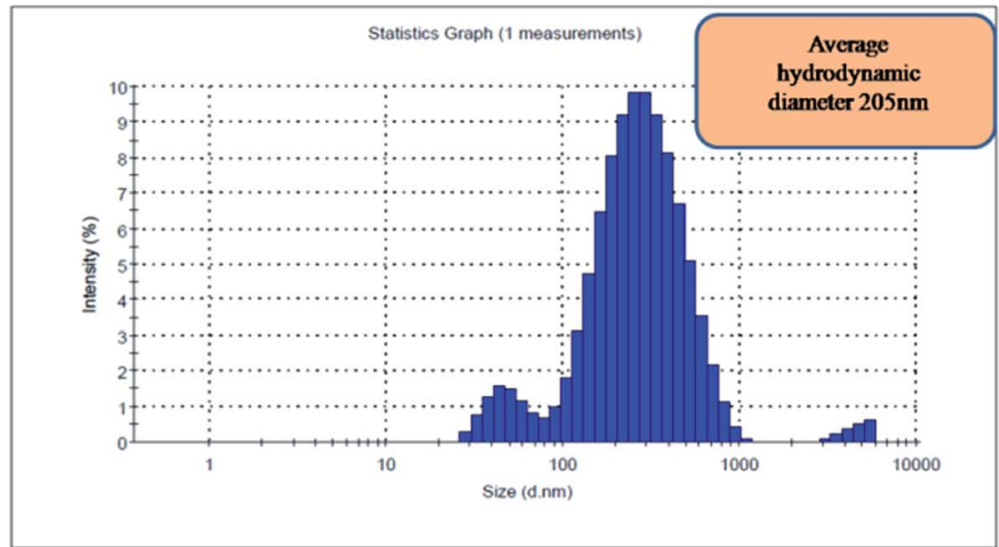

\section{B- $20 \mathrm{mmolC}_{16} \mathrm{MelmBr}$ in the presence of $18 \mathrm{mmol} \mathrm{DS}$}

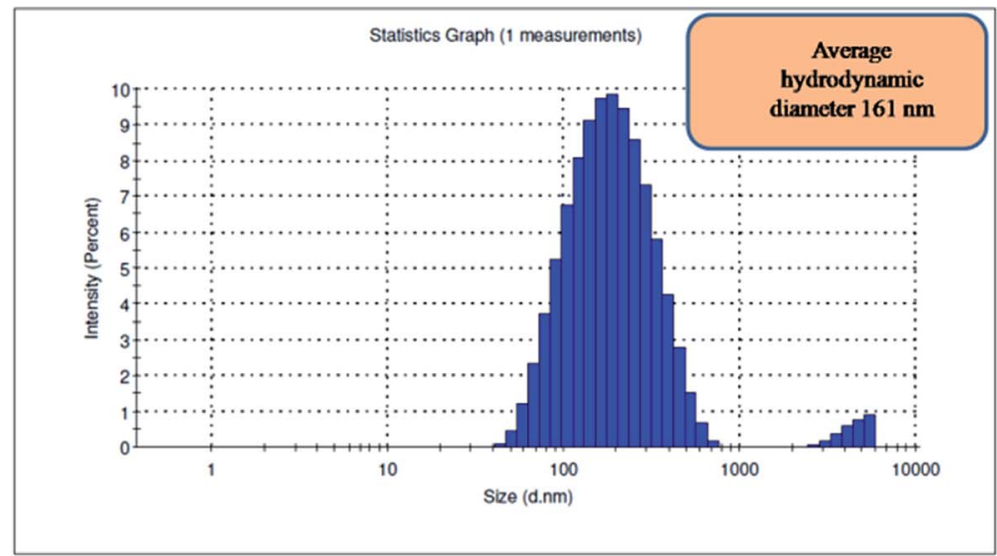

\section{C- $20 \mathrm{mmol} \mathrm{C}{ }_{16} \mathrm{Me}_{3} \mathrm{ABr}$ in the presence of $18 \mathrm{mmol} \mathrm{DS}$}

Fig. 6 DLS results showing the effects of DS (18 mmol) on the average hydrodynamic diameters $\left(D_{h}\right)$ of the amphiphilic aggregates present. Parts $(\mathrm{A}, \mathrm{B}, \mathrm{C})$ are for $\mathrm{C}_{16} \mathrm{VnlmBr}, \mathrm{C}_{16} \mathrm{MelmBr}$, and $\mathrm{C}_{16} \mathrm{Me}_{3} \mathrm{ABr}$, respectively.

$\mathrm{C}_{16} \mathrm{VnImBr}$. Further addition of DS above $13 \mathrm{mmol}$ leads to a viscosity drop, followed by precipitation and phase separation (for ILBSs), or precipitation (for $\mathrm{C}_{16} \mathrm{Me}_{3} \mathrm{ABr}$ ). Similar viscosity changes were previously reported for the addition of sodium tosylate to micellar $\mathrm{C}_{16} \mathrm{Me}_{3} \mathrm{ACl} .{ }^{66}$ Addition of DS to micellar solution of $\mathrm{C}_{16} \mathrm{VnImBr}, \mathrm{C}_{16} \mathrm{MeImBr}$ and $\mathrm{C}_{16} \mathrm{Me}_{3} \mathrm{ABr}$ decreases 


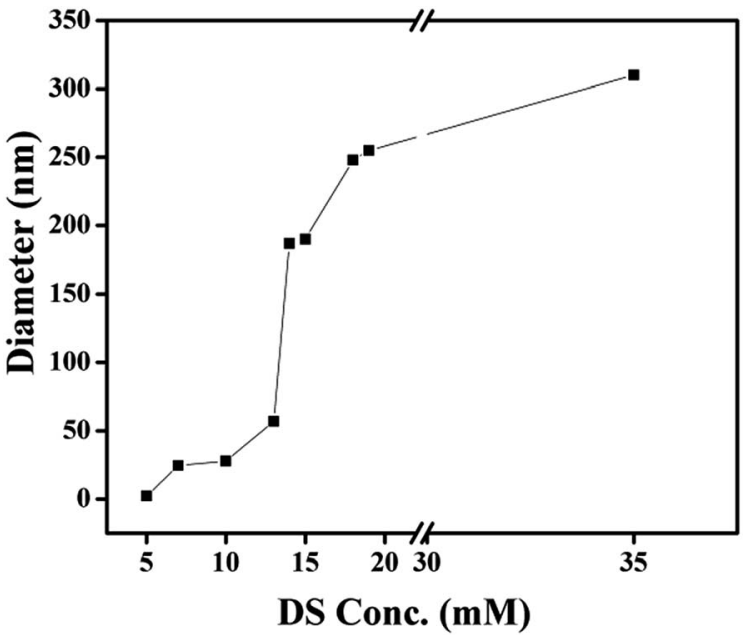

Fig. 7 Evolution of the average hydrodynamic diameters $\left(D_{h}\right)$ as a function of increasing the concentration of DS in the presence of fixed $\left[\mathrm{C}_{16} \mathrm{VnImBr}\right]$ of $20 \mathrm{mmol}$.

Table 1 Evolution of the average hydrodynamic diameters of different ILBSs as a functions of the molar ration (DS)/(surfactant) for the series $\mathrm{C}_{n} \mathrm{MelmBr}$

\begin{tabular}{llll}
\hline ILBS & $\begin{array}{l}{[\mathrm{DS}],} \\
\text { mmol }\end{array}$ & $\begin{array}{l}{[\mathrm{DS}] /\left[\mathrm{C}_{n} \mathrm{MeImBr}\right],} \\
\text { molar ratio }\end{array}$ & $\begin{array}{l}\text { Average } D_{\mathrm{h}}, \\
\mathrm{nm}\end{array}$ \\
\hline $\mathrm{C}_{12} \mathrm{MeImBr}$ & 50 & 0.5 & 164 \\
$\mathrm{C}_{14} \mathrm{MeImBr}$ & 25 & 0.5 & 190 \\
$\mathrm{C}_{16} \mathrm{MeImBr}$ & 18 & 0.9 & 161 \\
$\mathrm{C}_{16} \mathrm{VnImBr}$ & 14 & 0.7 & 189 \\
& 18 & 0.9 & 248 \\
& 35 & 1.75 & 310 \\
& 60 & 3.0 & 458 \\
\hline
\end{tabular}

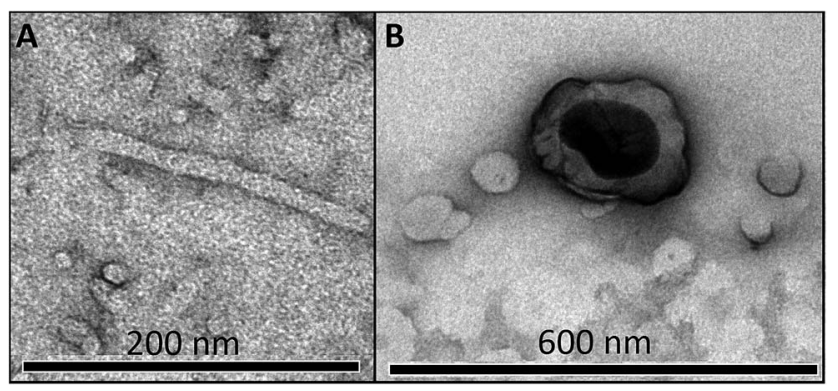

Fig. 8 TEM images for $20 \mathrm{mmol} \mathrm{C}_{16} \mathrm{Vn} / \mathrm{mBr}$ in the presence of $13 \mathrm{mmol}$ ( $\mathrm{A}$, worm-like micelle) and $19 \mathrm{mmol} \mathrm{DS}$ (vesicle) in aqueous solution. electrostatic repulsion between the head-groups of the aggregated molecules, in addition to hydrophobic interactions between the alkyl chain of the amphiphile and the aromatic rings of DS. This two-site binding of DS leads to the tight packing of ILBSs and $\mathrm{C}_{16} \mathrm{Me}_{3} \mathrm{ABr}$ monomers, which results in the growth of micelles and, finally, to formation of vesicles. The size and shape of the micelles were further confirmed using DLS and TEM, vide infra.

\section{Dynamic light scattering measurement (DLS)}

The effect of DS on hydrodynamic diameter $\left(D_{\mathrm{h}}\right)$ of micellar aggregates of the three surfactants in aqueous solution were evaluated using DLS using the cumulants method. As an example, we show in Fig. 6 the size distribution in a solution containing $18 \mathrm{mmol}$ DS and $20 \mathrm{mmol}$ surfactant. The evolution of the average hydrodynamic diameters $\left(D_{\mathrm{h}}\right)$ as a function of increasing [DS] at a fixed $\left[\mathrm{C}_{16} \mathrm{VnImBr}\right]$ is shown in Fig. 7.

For comparison, the average values of $D_{\mathrm{h}}$ of the corresponding aggregates in the absence of DS are: 5.1 [this work], 2.2 [this work], $0.9 \mathrm{~nm},{ }^{67}$ for $\mathrm{C}_{16} \mathrm{VnImBr}, \mathrm{C}_{16} \mathrm{MeImBr}$, and $\mathrm{C}_{16} \mathrm{Me}_{3} \mathrm{ABr}$, respectively.

The increase in $D_{\mathrm{h}}$ of each aggregate with increasing [DS] indicates growth of spherical micelles into vesicles via the intermediate formation of wormlike micelles, vide infra the results of TEM. As an example, consider the results of $\mathrm{C}_{16^{-}}$ VnImBr. At low concentration of DS $(5 \mathrm{mmol})$, the $D_{\mathrm{h}}$ of was $2.3 \mathrm{~nm}$, which is a typical diameter of spherical micelles of $\mathrm{C}_{16} \mathrm{VnImBr}^{64} \mathrm{An}$ increase of DS from $5 \mathrm{mmol}$ to $15 \mathrm{mmol}$ is accompanied with an increase of $D_{\mathrm{h}}$ and a large concomitant increase in solution viscosity, indicating the formation of rod/ wormlike micelles from spherical ones, see Fig. 5(a). Sharp increase in viscosity was observed at the same concentration range of DS. As [DS] was further increased, the drug-surfactant interactions increased, with concomitant decrease in the electrostatic repulsion between the surfactant head-groups. This resulted in tight packing of DS and the surfactant monomers, leading to an increase in $(P)$ and vesicle formation. As shown in Table 1 for $\mathrm{C}_{n} \mathrm{MeImBr}$ and $\mathrm{C}_{16} \mathrm{VnImBr}$, the effect of [DS] on the average $D_{\mathrm{h}}$ increases as a function of the length of the surfactant $\mathrm{C}_{n}$, an indication of the importance of the drug-surfactant hydrophobic interactions.

\section{Transmission electron microscopy (TEM)}

Parts (A and B) of Fig. 8 show micrographs for worm-like micelle and vesicle, respectively. Addition of DS causes a change of

Table 2 Morphological changes induced by the dissolution of DS ( $\mathrm{mmol})$ in micellar ILBSs (20 mmol)

\begin{tabular}{|c|c|c|c|c|c|c|}
\hline \multirow[b]{2}{*}{ Technique } & \multicolumn{3}{|l|}{$\mathrm{C}_{16} \mathrm{MeImBr}$} & \multicolumn{3}{|l|}{$\mathrm{C}_{16} \mathrm{VnImBr}$} \\
\hline & Vesicle & Phase separation & Precipitation & Vesicle & Phase separation & Precipitation \\
\hline Viscometry & $14-18$ and $>30$ & 19 and 25 & 20 & $14-19$ and $>35$ & 20 & $25-35$ \\
\hline DLS & 18 and 60 & & & $14-19$ and $>35$ & & \\
\hline TEM & 60 & & & 19,35 and 60 & & \\
\hline
\end{tabular}


aggregate morphology from spherical to worm like micelles and some small vesicles (13 mmol of DS; Fig. 8(A)) and finally into uni-lamellar vesicles (Fig. 8(B)), in agreement of the results of other techniques. The results of $\mathrm{C}_{16} \mathrm{MeImBr}$ and $\mathrm{C}_{16} \mathrm{VnImBr}$ shown in Table 2 indicate that vesicles are formed at lower [DS with $\mathrm{C}_{16} \mathrm{VnImBr}$ than with $\mathrm{C}_{16} \mathrm{MeImBr}$, probably due to interactions between the $\pi$-electrons of the drug and the vinyl group.

\section{Conclusions}

The DS-induced morphological changes of the micellar aggregates depend on the concentration of $\left(\mathrm{DS}^{-}\right)$and the structure of the surfactant head-group. From viscosity data we concluded that transition of spherical micelles to rod/wormlike micelles occurs at lower [DS] for $\mathrm{C}_{16} \mathrm{VnImBr}$ compare to $\mathrm{DS} / \mathrm{C}_{16} \mathrm{MeImBr}$ and $\mathrm{DS} / \mathrm{C}_{16} \mathrm{Me}_{3} \mathrm{ABr}$. This is a consequence of the presence of the vinyl group and possible $\pi-\pi$ interactions between the imidazolium heterocycle and the aromatic rings of DS. Turbidity, viscosity, DLS and TEM analyses revealed that vesicles were formed for $\mathrm{DS} / \mathrm{C}_{16} \mathrm{VnImBr}$ mixtures at lower [DS], as compared to $\mathrm{DS} / \mathrm{C}_{16} \mathrm{MeImBr}$ and $\mathrm{DS} / \mathrm{C}_{16} \mathrm{Me}_{3} \mathrm{ABr}$. The TEM micrographs corroborated the conclusions drawn from other techniques.

\section{Acknowledgements}

Z. S. Vaid thanks Maulana Azad National Research Fellowship (grant MANF-2012-13-MUS-GUJ-10818); N. I. Malek acknowledges financial assistances through Department of Science and Technology, New Delhi (SR/FT/CS-014/2010), Institute Research Grants to the Assistant Professors by SVNIT and Council of Scientific and Industrial Research (CSIR), New Delhi (Grant No. 01 (2545)/11/EMR-II). O. A. El Seoud thanks FAPESP and CNPq for financial support (2014/22136-4) and Research Productivity fellowship (307022/2014-5), respectively. We thank Dr Paulo A. R. Pires and Mr Alfredo Duarte for help with TEM images.

\section{References}

1 P. C. Hiemenz and R. Rajagopalan, Principles of colloid and surface chemistry, Marcel Dekker, New York, 3rd edn, 1997, ch. 8, pp. 355-404.

2 A. Manosroi, P. Wongtrakul, J. Manosroi, H. Sakai, F. Sugawara, M. Yuasa and M. Abe, Colloids Surf., B, 2003, 30, 129-138.

3 M. Cano-Sarabia, N. Ventosa, S. Sala, C. Patino, R. Arranz and J. Veciana, Langmuir, 2008, 24, 2433-2437.

4 F. Cuomo, F. Lopez, R. Angelico, G. Colafemmina and A. Ceglie, Colloids Surf., B, 2008, 64, 184-193.

5 T. Lian and R. J. Ho, J. Pharm. Sci., 2001, 90, 667-680.

6 P. Tanner, P. Baumann, R. Enea, O. Onaca, C. Palivan and W. Meier, Acc. Chem. Res., 2011, 44, 1039-1049.

7 D. G. Rhodes and A. Blazek-Welsh, Proniosome-Derived Niosomes for the Delivery of Poorly Soluble Drugs, ACS Symposium Series 879, American Chemical Society, Washington, DC, 2004.

8 L. Tavano, R. Muzzalupo, L. Mauro, M. Pellegrino, S. Ando and N. Picci, Langmuir, 2013, 29, 12638-12646.
9 J. G. Eastoe, J. Colloid Interface Sci., 2009, 330, 443-448.

10 R. Agarwal, O. P. Katare and S. P. Vyas, Int. J. Pharm., 2001, 228, 43-52.

11 Z. Wiesman, N. B. Dom, E. Sharvit, S. Grinberg, C. Linder, E. Heldman and M. Zaccai, J. Biotechnol., 2007, 130, 85-97.

12 Lv. Hongtao, S. Zhang, B. Wang, S. Cui and J. Yan, J. Controlled Release, 2006, 114, 100-109.

13 T. S. Davies, A. M. Ketner and S. R. Raghavan, J. Am. Chem. Soc., 2006, 128, 6669-6675.

14 M. Cano-Sarabia, A. Angelova, N. Ventosa, S. Lesieur and J. Veciana, J. Colloid Interface Sci., 2010, 350, 10-15.

15 S. Kumar and H. Patel, J. Mol. Liq., 2014, 190, 74-80.

16 R. D. Roger and K. R. Seddon, Ionic Liquids as Green Solvents: Progress and Prospects, American Chemical Society, Washington, D.C, 2003.

17 P. Wasserschein and T. Welton, Ionic liquids in syntheses, VCH-Wiley, Weinhein, 2003.

18 K. Behera, S. Pandey, A. Kadyan and S. Pandey, Sensors, 2015, 15, 30487-30503.

19 L. L. Sze, S. Pandey, S. Ravula, S. Pandey, H. Zhao, G. A. Baker and S. N. Baker, ACS Sustainable Chem. Eng., 2014, 2, 21172123.

20 C. Jungnickel, J. Luczak, J. Ranke, J. F. Fernandez, A. Muller and J. Thoming, Colloids Surf., A, 2008, 316, 278-284.

21 R. Vanyur, L. Biczok and Z. Miskolczy, Colloids Surf., A, 2007, 299, 256-261.

22 J. Luczak, C. Jungnickel, M. Joskowska, J. Thoming and J. Hupka, J. Colloid Interface Sci., 2009, 336, 111-116.

23 H. Zhang, K. Li, H. Liang and J. Wang, Colloids Surf., A, 2008, 329, 75-81.

24 A. Cornellas, L. Perez, F. Comelles, I. Ribosa, A. Manresa and M. T. Garcia, J. Colloid Interface Sci., 2011, 355, 164-171.

25 B. Dong, X. Zhao, L. Q. Zheng, J. Zhang, N. Li and T. Inoue, Colloids Surf., A, 2008, 317, 666-672.

26 F. Geng, J. Liu, L. Zheng, L. Yu, Z. Li, G. Li and C. Tung, J. Chem. Eng. Data, 2010, 55, 147-151.

27 O. A. El Seoud, P. A. R. Pires, T. Abdel-Moghny and E. L. Bastos, J. Colloid Interface Sci., 2007, 313, 296-304.

28 T. Inoue, H. Ebina, B. Dong and L. Zheng, J. Colloid Interface Sci., 2007, 314, 236-241.

29 N. V. Sastry, N. M. Vaghela and V. K. Aswal, Fluid Phase Equilib., 2012, 327, 22-29.

30 H. Wang, J. Wang, S. Zhang and X. Xuan, J. Phys. Chem. B, 2008, 112, 16682-16689.

31 M. Blesic, A. Lopes, E. Melo, Z. Petrovski, N. V. Plechkova, J. N. Canongia Lopes, K. R. Seddon and L. P. N. Rebelo, J. Phys. Chem. B, 2008, 112, 8645-8650.

32 T. Singh and A. Kumar, J. Phys. Chem. B, 2007, 111, 78437851.

33 N. M. Vaghela, N. V. Sastry and V. K. Aswal, Colloid Polym. Sci., 2011, 289, 309-322.

34 B. Dong, N. Li, L. Zheng, L. Yu and T. Inoue, Langmuir, 2007, 23, 4178-4182.

35 M. Ao and D. Kim, J. Chem. Eng. Data, 2013, 58, 1529-1534. 36 M. Anouti, J. Jones, A. Boisset, J. Jacquemin, M. C. Caravanier and D. Lemordant, J. Colloid Interface Sci., 2009, 340, 104-111. 
37 M. A. Rather, G. M. Rather, S. A. Pandit, S. A. Bhat and M. A. Bhat, Talanta, 2015, 131, 55-58.

38 N. Cheng, X. Ma, X. Sheng, T. Wang, R. Wang, J. Jiao and L. Yu, Colloids Surf., A, 2014, 453, 53-61.

39 A. Modaressi, H. Sifaoui, M. Mielcarz, U. Domanska and M. Rogalski, Colloids Surf., A, 2007, 302, 181-185.

40 X. Wang, J. Liu, L. Yu, J. Jiao, R. Wang and L. Sun, J. Colloid Interface Sci., 2013, 391, 103-110.

41 T. Singh, K. S. Rao and A. Kumar, J. Phys. Chem. B, 2012, 116, 1612-1622.

42 M. Blesic, M. H. Marques, N. V. Plechkova, K. R. Seddon, L. P. N. Rebelo and A. Lopes, Green Chem., 2007, 9, 481-490.

43 K. S. Rao, T. Singh, T. J. Trivedi and A. Kumar, J. Phys. Chem. B, 2011, 115, 13847-13853.

44 B. Dong, Y. Gao, Y. Su, L. Zheng, J. Xu and T. Inoue, J. Phys. Chem. B, 2010, 114, 340-348.

45 K. Srinivasa Rao, P. S. Gehlot, H. Gupta, M. Drechsler and A. Kumar, J. Phys. Chem. B, 2015, 119, 4263-4274.

46 J. Yuan, X. Bai, M. Zhao and L. Zheng, Langmuir, 2010, 26, 11726-11731.

47 M. Zhao, J. Yuan and L. Zheng, Colloids Surf., A, 2012, 407, 116-120.

48 S. Ghosh, C. Ghatak, C. Banerjee, S. Mandal, J. Kuchlyan and N. Sarkar, Langmuir, 2013, 29, 10066-10076.

49 P. Brown, C. P. Butts, J. Eastoe, I. Grillo, C. James and A. Khan, J. Colloid Interface Sci., 2013, 395, 185-189.

50 J. Kuchlyan, S. Ghosh, C. Banerjee, N. Kundu, D. Banik and N. Sarkar, J. Phys. Chem. B, 2014, 118, 5913-5923.

51 H. Wang, L. Zhang, J. Wang, Z. Lia and S. Zhang, Chem. Commun., 2013, 49, 5222-5224.

52 http://www.fiercepharma.com/special-report/top-20-genericmolecules-worldwide, accessed October 2016.
53 O. Singh, R. Kaur, V. K. Aswal and R. K. Mahajan, Langmuir, 2016, 32, 6638-6647.

54 N. I. Malek, Z. S. Vaid, U. U. More and O. A. El Seoud, Colloid Polym. Sci., 2015, 293, 3213-3224.

55 P. C. Hiemenz and R. Rajagopalan, Principles of Colloid and Surface Chemistry, Marcel Dekker, New York, 3 edn, 1997, p. 650.

56 CRC Handbook of Chemistry and Physics, Boca Raton, 85 edn, 2004.

57 C. Tanford, J. Phys. Chem., 1972, 76, 3020-3024.

58 T. L. Ferreira, O. A. El Seoud and M. Bertotti, J. Electroanal. Chem., 2007, 603, 275-280.

59 M. S. M. Rajputa, U. U. Morea, Z. S. Vaida, K. D. Prajapatib and N. I. Maleka, Colloids Surf., A, 2016, 507, 182-189.

60 E. W. Kaler, A. K. Murthy, B. E. Rodriguez and J. A. N. Zasadzinski, Science, 1989, 245, 1371-1374.

61 L. Li, Y. Yang, J. Dong and X. Li, J. Colloid Interface Sci., 2010, 343, 504-509.

62 T. A. Pascal and W. A. Goddard, J. Phys. Chem. B, 2014, 118, 5913-5923.

63 O. Pornsunthorntawee, S. Chavadej and R. Rujiravanit, J. Biosci. Bioeng., 2011, 112, 102-106.

64 R. Nagarajan, Langmuir, 2002, 18, 31-38.

65 K. Horbaschek, H. Hoffmann and C. Thunig, J. Colloid Interface Sci., 1998, 206, 439-456.

66 A. A. Ali and R. Makhloufi, Colloid Polym. Sci., 1999, 277, 270-275.

67 V. G. Rao, C. Ghatak, S. Ghosh, R. Pramanik, S. Sarkar, S. Mandal and N. Sarkar, J. Phys. Chem. B, 2011, 115, 38283837. 